REVIEW

\title{
Ventilator associated pneumonia
}

\author{
J D Hunter
}

Postgrad Med J 2006;82:172-178. doi: 10.1136/pgmj.2005.036905

Hospital acquired or nosocomial infections continue to be an important cause of morbidity and mortality. The critically ill patient is at particular risk of developing intensive care unit acquired infection, with the lungs being especially vulnerable. Nosocomial bacterial pneumonia occurring after two days of mechanical ventilation is referred to as ventilator associated pneumonia, and is the most common nosocomial infection seen in the intensive care unit. Intubation of the trachea and mechanical ventilation is associated with a 7 -fold to 21 -fold increase in the incidence of pneumonia and up to $28 \%$ of patients receiving mechanical ventilation will develop this complication. Its development is associated with an attributable increase in morbidity and mortality. The establishment of an accurate diagnosis of ventilator associated pneumonia remains problematic and as yet there is still no accepted "gold standard" for diagnosis. The responsible pathogens vary according to case mix, local resistance patterns, and methodology of sampling. However, there is general agreement that rapid initiation of appropriate antimicrobial therapy improves outcome.

Correspondence to: Dr J D Hunter, Department of Anaesthetics and Intensive Care,

Macclesfield District

General Hospital, Victoria Road, Macclesfield SK10

3BL, UK; john.hunter@ echeshire-tr.nwest.nhs.uk

Submitted 5 May 2005 Accepted 4 July 2005
V entilator associated pneumonia (VAP) is defined as nosocomial pneumonia occurring in a patient after 48 hours of mechanical ventilation via a tracheal or tracheostomy tube. It is commonly classified as either early onset (occurring within 96 hours of start of mechanical ventilation) or late onset ( $>96$ hours after start of mechanical ventilation). It is a common condition, difficult to diagnose accurately, and expensive to treat. Its development prolongs a patient's stay in the intensive care unit (ICU), and is associated with significant morbidity and mortality. Most cases seem to result from aspiration of pathogenic material that commonly colonises the oropharyngeal airways of the critically ill. Simple measures to decrease the incidence of aspiration or reduce the burden of colonisation of the oropharynx may aid in the prevention of ventilator associated pneumonia. A favourable outcome seems to be more likely if appropriate antibiotics are given in a timely manner.

\section{EPIDEMIOLOGY}

Accurate information concerning the epidemiology of VAP is lacking, as there is no universally accepted criteria for its diagnosis. Its incidence is also influenced by the case mix studied, and prior exposure to antibiotics. A one day point prevalence study designed to determine the prevalence of ICU acquired infection identified pneumonia as the most common infection with a prevalence of $10 \%$, although this may not be wholly accurate as no strict diagnostic criteria were stipulated. ${ }^{1}$ However, the clinical course of up to $28 \%$ of patients receiving mechanical ventilation will be complicated by an episode of VAP and intubated patients have rates of pneumonia up to 21 times higher than patients without an artificial airway. ${ }^{2-6}$

The mortality attributable to VAP is difficult to quantify as it is influenced by many different factors including type of infecting organism, underlying comorbidity, severity of host response, and timing of onset. However, VAP does seem to be associated with a significantly higher risk of death. Of seven studies performed using matched controls, five have shown a significant increase in mortality attributable to VAP. $^{2}{ }^{7-12}$

The development of VAP prolongs the stay in the ICU and is associated with an increase in costs. ${ }^{13}$ A study by Heyland and colleagues to determine the excess ICU stay attributable to VAP prospectively matched patients with VAP to patients who did not develop clinically suspected pneumonia. They found that the development of VAP was associated with an average of 4.3 days longer in the ICU than control subjects. ${ }^{2}$ Other studies support these findings. ${ }^{14} 15$

\section{PATHOGENESIS}

Pneumonia represents the host's inflammatory response to the microbial invasion of the normally sterile lung parenchyma. The magnitude of this response depends on the size and type of the inoculum, the virulence of the organisms involved, and the competence of the host's immune system.

Most cases of VAP are caused by the aspiration of infected secretions from the oropharynx, although a small number of cases may result from direct bloodstream infection. ${ }^{16}{ }^{17}$ Critical illness leads to the rapid colonisation of the oropharynx with potentially pathogenic bacteria caused by changes in host defences, previous antibiotic exposure, and changes in either the bacterial adhesins or host surface receptors. ${ }^{18}$ Aerobic Gram negative bacteria (AGNB) and Staphylococcus aureus rapidly replace normal flora. Other potential sources of infected material

Abbreviations: VAP, ventilator acquired pneumonia; ICU, intensive care unit; $A G N B$, aerobic Gram negative bacteria; TREM-1, triggering receptor expressed on myeloid cells; BAL, bronchoalveolar lavage; PSB, protected specimen brushing 
include the sinuses and dental plaque. It remains contentious whether the aspiration of infected material from the stomach plays an important part in the development of VAP. ${ }^{19-21}$ However, alkalinisation of the normally acid environment in the stomach leads to overgrowth with AGNB, providing a potential pool of infected material..$^{22}$

The presence of the cuff on the tracheal tube does not prevent the passage of infected material into the airways. ${ }^{23}$ Contaminated secretions pool above the high volume low pressure cuff of the tracheal tube commonly used in ICU, and gain access to the trachea along folds in the cuff. These organisms can then gain access to and colonise the biofilm that rapidly coats the inner surface of the tracheal tube. ${ }^{24}$ This is commonly followed by colonisation of the trachea with pathogenic organisms. The infected material is then propelled into the distal airways by the inspiratory flow provided by the mechanical ventilator. Occasionally, contaminated nebulisers, ventilation circuits or humidifiers may be the source of the infected material. ${ }^{25}$

A variety of defence mechanisms exist that protect the lung from infection including non-immune antimicrobial agents in saliva, an intact cough reflex, mucociliary clearance, and cell mediated and humoral immunity. Indeed, healthy adults frequently aspirate oropharyngeal secretions with impunity because of host defence mechanisms. ${ }^{26}$ However immune dysfunction is well reported in the critically ill and many of these host defence mechanisms are ineffective. ${ }^{27}$ When infected material reaches the distal airways, the immune mechanisms within the lung attempt to inactivate or kill the offending organism(s). Alveolar macrophages, neutrophils, and elements of the humoral immune system interact to mount an inflammatory response. ${ }^{28}{ }^{29}$ If the host's immune system is overwhelmed, then pneumonia develops.

Acute lung injury and acute respiratory distress syndrome are commonplace in the critically ill and are associated with profound changes in the structure and functioning of the alveoli. Martin and colleagues showed that the function of neutrophils obtained from bronchoalveolar lavage fluid of patients with acute respiratory distress syndrome is significantly impaired. ${ }^{30}$ These changes impair the ability of the lungs defence mechanisms to deal with a bacterial challenge. Pulmonary oedema and alveolar haemorrhage also provide a favourable environment for the proliferation of bacteria. ${ }^{31}$

\section{RISK FACTORS}

Multiple factors have been identified that increase the likelihood of developing VAP (see box).

Intubation is the most important risk factor for developing nosocomial pneumonia. ${ }^{32}$ Although it is difficult to differentiate between the risk imposed by the mechanical ventilator and its associated tubing and the presence of a

\section{Risk factors for the development of ventilator} associated pneumonia

- Age $\geqslant 60$ years

- Severity of illness (APACHE II score >16)

- Acute or chronic lung disease

- Excessive sedation

- Enteral nutrition

- Severe burns

- Supine body position

- Glasgow coma scale<9

- Use of muscle relaxants

- Cigarette smoking tracheal tube, it is known that the incidence of VAP is less when non-invasive ventilation is used. ${ }^{33}{ }^{34}$

Stress ulcer prophylaxis is routinely used in the critically ill. $\mathrm{H}_{2}$ blockers or the gastroprotective agent sucralfate form the mainstay of treatment. The use of $\mathrm{H}_{2}$ blockers is associated with a change in the acidity of the gastric juices that favours bacterial colonisation with Gram negative bacteria. ${ }^{35}$ However, the role of gastric $\mathrm{pH}$ in the pathogenesis of VAP is controversial. A large, multicentre, randomised, blinded placebo controlled trial involving 1200 mechanically ventilated patients in which sucralfate was compared with the $\mathrm{H}_{2}$ receptor antagonist ranitidine for the prevention of upper gastrointestinal bleeding failed to show any difference in the incidence of VAP. ${ }^{36}$ However, a number of other studies suggest that lower rates of VAP are seen in patients given a gastroprotective agent rather than agents that block gastric acid secretions. ${ }^{37}$ Despite these discordant results, $\mathrm{H}_{2}$ receptor antagonists are widely used and most clinicians believe that the use of these agents to prevent stress ulcer bleeding outweighs any additional risk of VAP. ${ }^{39}$

There is an increasing awareness of the importance of body position on the development of VAP. ${ }^{40}$ Drakulovic and colleagues randomly allocated intubated mechanically ventilated patients to be nursed in either the semi-recumbent $\left(45^{\circ}\right)$ or the supine body position. ${ }^{41}$ Microbiologically confirmed pneumonia developed in significantly fewer patients nursed in the semi-recumbent position (2 of 39 [5\%]) than in those nursed supine ( 11 of 47 [23\%], $p=0.018$ ). The exact mechanism by which adoption of the semi-recumbent position decreases the incidence of nosocomial pneumonia is not completely understood, but is probably related to the reduction in gastro-oesophageal reflux seen in this position.

Unplanned or failed extubation followed by re-intubation has been identified as a significant risk factor for the development of $\mathrm{VAP}^{42}$ It is probable that aspiration of infected upper airway secretions occurs at the time of reintubation.

Nasal intubation, by blocking sinus outflow via the nasal ostia, is associated with a higher incidence of nosocomial sinusitis. ${ }^{43}$ However, it remains inconclusive whether nasal intubation is associated with a higher incidence of VAP. In a trial by Holzapfel and colleagues in which a total of 300 adult mechanically ventilated patients were randomised to either oro-tracheal or nasal intubation, no statistically significant difference in the occurrence of VAP could be shown between the groups despite more sinusitis in the nasotracheal group. ${ }^{44}$

Enteral feeding via a nasogastric tube promotes gastrooesophageal reflux, the magnitude of which is unchanged by the use of fine bore tubes. ${ }^{45}$ It is also associated with an increase in gastric $\mathrm{pH}$ and colonisation of the stomach with AGNB.$^{46}$ It is therefore unsurprising that enteral nutrition has been shown to be an independent risk factor for the development of VAP (odds ratio 5.7 (95\% CI 1.5 to 22.8), $\mathrm{p}=0.013) .^{41}$ However, as adequate nutrition is essential in the critically ill and the enteral route is generally regarded as superior to parenteral nutrition, most clinicians advocate the commencement of early nasogastric feeding. ${ }^{47}$

\section{DIAGNOSIS OF VAP}

The accurate diagnosis of VAP remains problematic. Standard diagnostic features of pneumonia such as fever, tachycardia, leucocytosis, purulent sputum, and consolidation on the chest radiograph are unreliable in the critically ill mechanically ventilated patient. Fever, leucocytosis, and tachycardia are non-specific findings and are seen in any critically unwell patient with an inflammatory response to an insult, for example, trauma, burns, pancreatitis, etc. Purulent sputum may be caused by tracheobronchitis and does not always signify parenchymal involvement. ${ }^{48}$ Infiltrates on the chest 


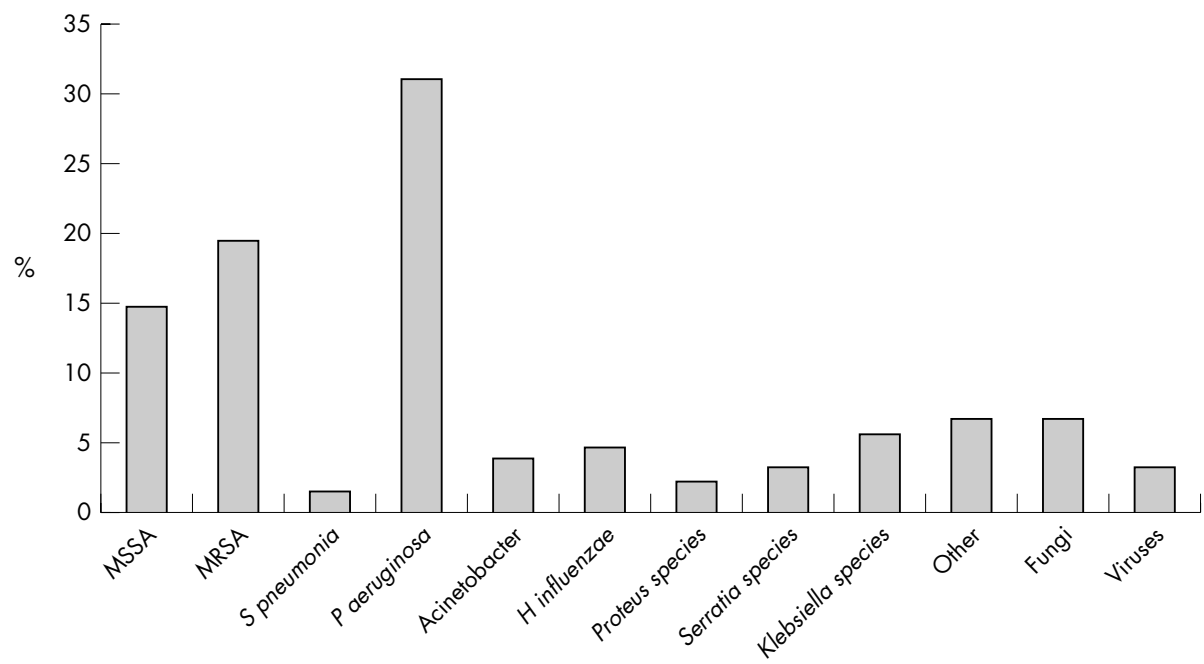

Figure 1 Summary of pathogens responsible for VAP in a study of 420 patients. Adapted from Cerra et al. ${ }^{47}$ MSSA, methicillin sensitive Straphylococcus aureus; MRSA, methicillin resistant Straphylococcus aureus.

radiograph can be caused by a number of non-infective conditions including pulmonary oedema, haemorrhage, and contusions. ${ }^{49}$ A study by Meduri and colleagues highlighted some of these difficulties. In a prospective study of 50 patients with fever and pulmonary infiltrates, only $42 \%$ had a definitive diagnosis of VAP. ${ }^{50}$ Disappointingly the use of scoring systems, such as the clinical pulmonary infection score, seems to add little to diagnostic accuracy. ${ }^{51}$

Nevertheless, the diagnosis of VAP is suspected if the patient has a new or progressive infiltrate on the chest radiograph accompanied by clinical findings suggestive of

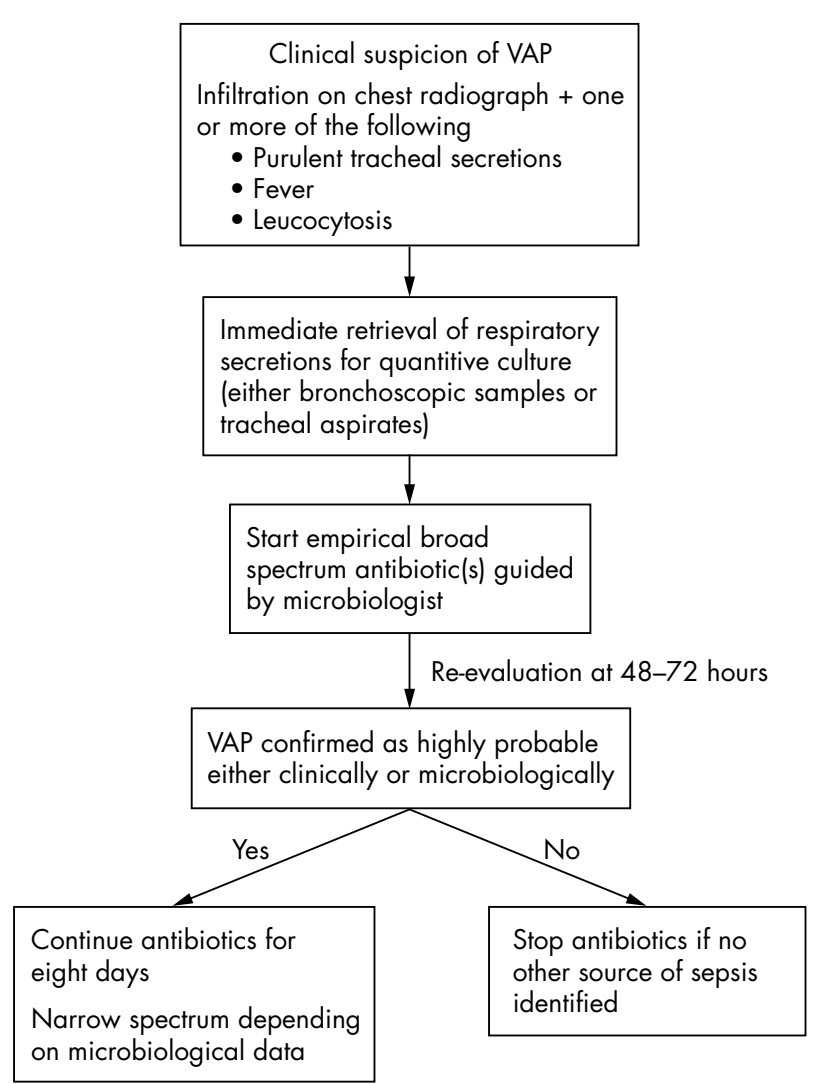

Figure 2 A simplified strategy for the management of suspected VAP. Adapted from Torres et al. ${ }^{74}$ infection such as fever, leucocytosis, and purulent secretions. This is often accompanied by deterioration in gas exchange.

Because clinical suspicion alone is overly sensitive and lacks specificity, further diagnostic tests are required for optimal management. Ideally, microbiological data should be obtained before the start of antibiotic therapy.

\section{Microbiological diagnosis}

Despite numerous publications on the subject, controversy still exists on the optimal method of microbiological diagnosis of VAP..$^{52}$ As the trachea and tracheal tube rapidly become colonised with bacteria in the critically ill patient, cultures of sputum or tracheal aspirates may simply yield colonising organisms. The argument therefore revolves around whether specimens of lower respiratory tract secretions should be collected in an invasive manner or whether quantitative analysis of non-invasively collected tracheal aspirates is sufficient. Analysing samples using quantitative culture techniques theoretically permits differentiation between oropharyngeal organisms present at low concentrations and the higher concentrations of pathogenic organisms.

Blood cultures have limited value in the diagnosis of VAP and have a very low sensitivity for detecting the pathogenic organism responsible for the pneumonia. However, blood cultures are obviously useful in any patient with signs of sepsis, but the isolation of a micro-organism in the blood does not confirm that micro-organism as the pathogen responsible for VAP. ${ }^{53}$

A recently described immunological method for the diagnosis of VAP holds great promise for the future. The triggering receptor expressed on myeloid cells (TREM-1) is a member of the immunoglobulin superfamily, and is involved in the acute inflammatory response. Neutrophils express high levels of TREM-1 on exposure to infected tissues. Gibot and colleagues prospectively studied 148 mechanically ventilated patients with suspected VAP. A rapid immunoblot technique was used to measure soluble TREM-1 in bronchoalveolar lavage fluid. They showed that the presence of soluble TREM1 in the bronchoalveolar lavage (BAL) fluid was a highly accurate method for the diagnosis of fungal or bacterial pneumonia with a sensitivity of $98 \%$ and a specificity of $90 \% .^{54}$

\section{Quantitative cultures of tracheal aspirates}

Collection of material for microbiological analysis using this technique is quick, simple, and widely available. While there is some evidence to suggest that the use of this method has a high false positive rate in the diagnosis of VAP, other studies 
suggest that quantitative analysis of tracheal aspirates offers a reliable alternative to invasive techniques. ${ }^{55-57}$ A prospective study by Sanchez-Nieto and colleagues comparing quantitative analysis on non-invasively collected tracheal aspirates with invasively collected respiratory samples in 51 patients with suspected VAP showed a high degree of concordance in bacteriological results and no difference in mortality. ${ }^{55}$ Another study involving 76 patients with suspected VAP, who were randomly allocated to either invasive or a noninvasive diagnostic strategy, also showed that the invasive strategy had no benefit. ${ }^{58}$ Both studies used a threshold of $10^{5}$ colony forming units/ml to distinguish tracheal colonisation from true VAP.

A non-invasive strategy of diagnosis in those suspected of VAP seems to be associated with higher antibiotic use. ${ }^{59}$

\section{Invasive techniques of sampling distal airways}

Fibre optic bronchoscopy allows direct selective access to the distal airways for sampling. However, there are a number of problems associated with the use of bronchoscopy; the expertise and equipment required is not always available and sampling is often followed by a period of hypoxaemia. ${ }^{60}$ Accurate results also require rigorous microbiological analysis in laboratories with specialised equipment.

Whether an invasive approach changes outcome remains contentious. Three comparatively small single centre studies comparing mortality in patients with suspected VAP managed on the results obtained by either invasive studies or quantitative analysis of tracheal aspirates failed to find any difference in mortality. ${ }^{55861}$ A much larger study involving 413 patients suspected of having VAP suggested that an invasive diagnostic strategy was desirable..$^{59}$ Compared with patients who received clinical management, patients who received invasive management had reduced mortality rate at day $14(16.2 \%$ and $25.8 \%, p=0.02)$ and decreased antibiotic use (mean (SD) number of antibiotic free days, 5.0 (5.1) and 2.2 (3.5), p<0.001). Most recently a meta-analysis of randomised, controlled trials of invasive diagnostic strategies in suspected VAP reported that an invasive approach did not change mortality (odds ratio $0.89,95 \%$ confidence interval 0.56 to 1.41 ), but did change antibiotic use (odds ratio for change in antibiotic management after invasive sampling, $2.85,95 \%$ confidence interval 1.45 to 5.59$).{ }^{62}$

Two techniques are commonly used to obtain distal airway samples with the bronchoscope; BAL or protected specimen brushing (PSB).

\section{Bronchoalveolar lavage}

BAL is performed by advancing the bronchoscope into a distal airway and instilling about $130-150 \mathrm{ml}$ of sterile saline. ${ }^{63}$ Selection of the area of the lung for sampling is guided by the pattern of consolidation on the chest radiograph. As much of the saline a possible is aspirated and sent for quantitative culture. The most frequently used threshold for a positive culture is $10^{4}$ colony forming units $/ \mathrm{ml}$. An examination of 23 studies evaluating the accuracy of BAL methods using fibreoptic bronchoscopy to diagnose VAP reported a mean (SD) sensitivity of $73 \%(18 \%)$ and a mean (SD) specificity of $82 \%(19 \%) .^{63}$

\section{Protected specimen brush}

This technique was introduced in 1979 by Wiberley et al in an attempt to reliably obtain lower respiratory tract specimens that are not contaminated with tracheal or tracheal tube organisms. ${ }^{64}$ This technique entails the advancement of a double lumen catheter system under direct vision into the desired distal airway. Once in position the brush is advanced expelling the carbowax plug at the distal end of the catheter. Brushings are taken and the brush is then retracted into the catheter and removed, thereby protecting the brush from contamination. The brush is suspended in $1 \mathrm{ml}$ of saline and quantitative culture obtained. A threshold of $10^{3}$ colony forming units $/ \mathrm{ml}$ is used to signify a positive result. Pooled data from 18 studies show that the diagnostic accuracy of this technique is high, with a sensitivity of $89 \%$ (95\% confidence interval, $87 \%$ to $93 \%$ ) and a specificity of $94 \%$ (95\% confidence interval, $92 \%$ to $97 \%$ ). ${ }^{65}$

\section{Non-bronchoscopic sampling of distal airways}

BAL and PSB can both be performed without the aid of a bronchoscope. Non-bronchoscopic BAL is performed by blindly advancing a protected suction catheter through the tracheal tube until it becomes wedged in a distal airway. The inner cannula is then advanced past its protective sheath and $100 \mathrm{ml}$ of saline introduced and aspirated. Non-bronchoscopic PSB is similarly performed by inserting a double lumen catheter through the tracheal tube until resistance is felt and then advancing the brush to obtain a specimen. The good concordance between microbiological data obtained by bronchoscopic and non-bronchoscopic techniques shows the diffuse nature of parenchymal infection in those with VAP. ${ }^{66}$

\section{PATHOGENS}

The organisms responsible for VAP vary according to case mix, institution, prior antibiotic exposure, local resistance patterns, and length of mechanical ventilation. Organisms responsible for early onset VAP are largely Staphylococcus aureus, Streptococcus pneumoniae, and Haemophilus influenzae while late onset VAP is often caused by resistant nosocomial pathogens such as Pseudomonas aeruginosa, methicillin resistant Staphylococcus aureus, Klebsiella species, and Acinetobacter baumannii. Figure 1 shows the range of organisms responsible for VAP in an important recent study ${ }^{67}$ The isolation of MRSA is more common in elderly patients, and those who have received prior antibiotic therapy. ${ }^{68}$

\section{MANAGEMENT OF SUSPECTED VAP}

Optimal management of the patient with suspected VAP requires prompt initiation of appropriate antimicrobial therapy and general supportive care. Although microbiological sampling should be performed before start of therapy, this must not delay commencement of antibiotic dosing. ${ }^{39} 69$ Several studies show that delay in administration of effective therapy is associated with an increase in mortality rate. ${ }^{70} 71$

\section{Key references}

- Chastre J, Fagon JY. Ventilator-associated pneumonia. Am J Respir Crit Care Med 2002;165:867-903.

- Kollef MH. The prevention of ventilator-associated pneumonia. N Engl J Med 1999;340:627-34.

- Rello J, Artur Paiva J, Baraibar J, et al. International conference for the development of consensus on the diagnosis and treatment of ventilator-associated pneumonia. Chest 2001;120:955-70.

- Rello J, Diaz E. Pneumonia in the intensive care unit. Crit Care Med 2003;31:2544-51.

- Hubmayr RD, Burchardi H, Elliot M, et al. American Thoracic Society Assembly on Critical Care; European Respiratory Society; European Society of Intensive Care Medicine; Societe de Reanimation de Langue Francaise. Statement of the 4th international consensus conference in critical care on ICU-acquired pneumonia-Chicago, Illinois, May 2002. Intensive Care Med 2002;28:1521-36. 
A detailed discussion of appropriate antibiotic regimens is beyond the scope of this article and each ITU should tailor its own regimens to the local microbial epidemiology and susceptibility patterns. This requires close liaison with the hospitals' microbiology service. However, because of the plethora of potential causative organisms a broad spectrum antibiotic should be given initially with activity against enteric Gram negative organisms. In patients with early onset VAP who have not previously received antibiotic therapy, monotherapy with a third generation cephalosporin (for example, cefotaxime) is a reasonable choice. For patients who develop VAP after prolonged mechanical ventilation and prior antibiotic exposure, a combination of antibiotics is required to ensure adequate coverage of potential pathogens. Piperacillin/tazobactam (Tazocin) with a combination of either aminoglycoside or ciprofloxacillin is the preferred choice for empiric therapy. ${ }^{52}$ A prospective study of 156 patients with clinically suspected VAP showed that those who received initial empiric therapy with antipseudomonal penicillins plus $\beta$ lactamase inhibitor had lower in-hospital mortality compared with those who were not treated with these antibiotics. There was also a strong trend towards reduced mortality rates when gentamicin was given as part of the antibiotic regimen. ${ }^{72}$ Alternatively, an antipseudomonal carbapenem (for example, Meropenem) or an antipseudomonal cephalosporin (for example, Ceftazidime) can be given with either a fluoroquinolone or an aminoglycoside. ${ }^{4}$ The aminoglycosides should not be used as monotherapy as lung penetration is poor. An antibiotic with activity against MRSA should also form part of the antibiotic regimen if MRSA is a possibility. This is especially probable in those patients who have received prior antibiotic therapy. ${ }^{68}$ Although the glycopeptide antibiotics teicoplanin and vancomycin form the mainstay of therapy against nosocomial pneumonia attributable to MRSA, there is limited evidence to suggest that the newer agent linezolid is associated with significantly better survival and clinical cure rates than vancomycin in patients with VAP. ${ }^{73}$

Inappropriate or inadequate therapy is associated with excess mortality, and longer length of stay. ${ }^{74}$ Subsequent culture data from microbiological samples should be used to tailor antibiotic therapy when it becomes available. ${ }^{75}$ Figure 2 outlines a straightforward algorithm for the management of suspected VAP. ${ }^{76}$

The optimal duration of antimicrobial treatment for VAP is unknown. In a randomised, prospective clinical trial of over 400 patients 8 and 15 days of antibiotic therapy was compared for VAP. This study showed comparable clinical effectiveness with the 8 and 15 day treatment regimens. In particular, there was no excess mortality or increase in microbiologically reported pulmonary infection recurrence in the 8 day group. ${ }^{77}$

\section{PREVENTION OF VAP}

There are several measures that can be taken to reduce the incidence of VAP. Strict hand washing and the use of protective gowns and gloves should be routinely used in the ICU to minimise nosocomial infections. ${ }^{17}{ }^{78}$ Patients should be nursed in the semi-recumbent position ( $45^{\circ}$ angle), gastric distension avoided, and there should not be any unnecessary changes of the ventilator circuit. Nasal intubation should be discouraged and there is increasing evidence to suggest that performance of an early tracheostomy in patients expected to require prolonged mechanical ventilation is beneficial. In a recent study of 120 patients expected to require mechanical ventilation for longer than 14 days, those that were randomised to receive percutaneous dilatational tracheostomy within 48 hours of admission had a significantly lower incidence of VAP than those who received a tracheostomy after $14-16$ days (5\% compared with $25 \%$, p <0.005). ${ }^{79}$ Daily interruption of sedative drug infusions has been shown to shorten the duration of mechanical ventilation. ${ }^{80}$ There is some evidence to suggest that prophylactic parenteral antibiotics may be useful in the prevention of VAP, especially those with a significantly obtunded conscious level. ${ }^{81}$

Many ICUs are introducing "ventilator bundles", which are a group of interventions related to patients receiving mechanical ventilation that, when implemented together, result in better outcomes than when implemented individually. Some of the key components of the bundles such a positioning of the patient and avoidance of heavy sedation may reduce the incidence of VAP.

\section{SUMMARY}

VAP continues to be an important challenge to the critical care physician and is the most common nosocomial acquired infection among patients with acute respiratory failure. It is difficult to diagnose accurately, and a high index of suspicion is required. If VAP is suspected empirical antibiotics should be given immediately. Although bacteriological sampling is important, it should not significantly delay the start of treatment. As the appropriateness of the initial antibiotic regimen is a vital determinant of outcome, microbiological advice should be sought. There is an increasing prevalence of MRSA and multidrug resistant pathogens in late onset VAP, and antimicrobial therapy should take account of this. Subsequent microbiological findings should be used to tailor antibiotic therapy.

Several, easy to implement strategies have been identified that prevent VAP and these should be used in all ventilated patients. The introduction of "ventilator bundles" may facilitate this.

\section{MULTIPLE CHOICE QUESTIONS (TRUE (T)/FALSE (F); ANSWERS AT THE END OF THE REFERENCES)}

1. Which of the following statements is true regarding ventilator associated pneumonia

(A) VAP is the most commonly observed nosocomial infection in the intensive care unit

(B) There are universally accepted diagnostic criteria

(C) The development of VAP has no influence on patient length of stay

(D) In excess of $25 \%$ of patients receiving intubation and mechanical ventilation will develop VAP

2. Regarding the pathogenesis of VAP;

(A) VAP is normally caused by haematogenous spread of organisms

(B) A well inflated tracheal tube cuff will reliably prevent aspiration

(C) The aspiration of infected material from the stomach plays an important part in the development of VAP

(D) Acute lung injury does not predispose the patient to the development of VAP

3. The following are confirmed risk factors for the development of VAP

(A) Nursing the patient in a supine position

(B) Enteral feeding

(C) The use of sucralfate as stress ulcer prophylaxis

(D) Obtunded conscious level at the time of intubation

4. Regarding the diagnosis of VAP, which of the following statements are true; 
(A) Microbiological specimens should be processed in a non-quantitative manner

(B) A specimen obtained by bronchoalveolar lavage containing $>10^{3}$ colony forming units $/ \mathrm{ml}$ signifies invasive infection

(C) Blood cultures have a high sensitivity for detecting the organisms responsible for VAP

(D) A bronchoscope is always required to sample the distal airways

5. The optimal management of VAP always requires;

(A) Identification of the responsible pathogen before the start of antibiotic treatment

(B) An antifungal agent as part of the antibiotic regimen

(C) Close liaison with microbiology service

(D) A microbiological sample obtained from the distal airways

Funding: none.

Conflicts of interest: none declared.

\section{REFERENCES}

1 Vincent JL, Bihari DJ, Suter PM, et al. The prevalence of nosocomial infection in intensive care units in Europe. Results of the European prevalence of infection in intensive care (EPIC) study. JAMA 1995;274:639-44.

2 Heyland DK, Cook DJ, Griffith L, et al. The attributable morbidity and mortality of ventilator-associated pneumonia in the critically ill patient. The Canadian Critical Trials Group. Am J Respir Crit Care Med 1999;159:1249-56.

3 Celis R, Torres A, Gatell JM, et al. Nosocomial pneumonia. A mulitivariate analysis of risk and prognosis. Chest 1988;93:318-24.

4 Chastre J, Fagon JY. Ventilator-associated pneumonia. Am J Respir Crit Care Med 2002; 165:867-903.

5 Haley RW, Hooton TM, Culver TH, et al. Nosocomial infection in US hospitals 1975-76. Estimated frequency by selected characteristics of patients. Am J Med 1981;70:947-59.

6 Chevret S, Hemmer M, Carlet J, et al. Incidence and risk factors of pneumonia acquired in intensive care units. Results from a multi-centre prospective study on 996 patients. European Cooperative Group on Nosocomial Pneumonia. Intensive Care Med 1993;19:256-64.

7 Fagon JY, Chastre AJ, Hance AJ, et al. Nosocomial pneumonia in ventilated patients: a cohort study evaluating attributable mortality and hospital stay. Am J Med 1993;94:281-8.

8 Bercault N, BoulainT. Mortality rate attributable to ventilator-associated nosocomial pneumonia in an adult intensive care unit: a prospective casecontrol study. Crit Care Med $2001 ; 29: 2303-9$.

9 Craig CP, Connelly S. Effect of intensive care unit nosocomial pneumonia on duration of stay and mortality. Am J Infect Control 1984;12:233-8.

10 Baker AM, Meredith JW, Haponik EF. Pneumonia in intubated trauma patients. Microbiology and outcome. Am J Respir Crit Care Med 1996;153:343-9.

11 Cunnion KM, Weber DJ, Broadhead WE, et al. Risk factors for nosocomial pneumonia: comparing adult critical care populations. Am J Respir Crit Care Med 1996;153:158-62.

12 Papazian L, Bregeon F, Thirion X, et al. Effect of ventilator-associated pneumonia on mortality and morbidity. Am J Respir Crit Care Med 1996;154:91-7.

13 Pinner RW, Haley RW, Blumenstein BA, et al. High cost nosocomial infections. Infect Control 1982;3:143-9.

14 Craig CP, Connelly S. Effect of intensive care unit nosocomial pneumonia on duration of stay and mortality. Am J Infect Control 1984;12:233-8.

15 Kappstein I, Schulgen G, Beyer U, et al. Prolongation of hospital stay and extra costs due to ventilator-associated pneumonia in an intensive care unit. Eur J Clin Microbiol Infect Dis 1992;11:504-8.

16 Estes RJ, Meduri GU. The pathogenesis of ventilator-associated pneumonia: I. Mechanisms of bacterial transcolonization and airway inoculation. Intensive Care Med 1995;21:365-83.

17 Kollef MH. The prevention of ventilator-associated pneumonia. N Engl J Med 1999;340:627-34

18 Garrouste-Orgeas M, Chevret S, Arlet G, et al. Oropharyngeal or gastric colonization and nosocomial pneumonia in adult intensive care unit patients. A prospective study based on genomic DNA analysis. Am J Respir Crit Care Med 1997; 156:1647-55.

19 Bonten MJ, Gaillard CA, van Tiel FH, et al. The stomach is not a source for colonization of the upper respiratory tract and pneumonia in ITU patients. Chest 1994; 105:878-84.

20 Craven DE, Steger KA, Barber TW. Preventing nosocomial pneumonia: state of the art and perspectives for the 1990's. Am J Med 1991;91:44-53.

21 Du Moulin GC, Paterson DG, Hedley-Whyte J, et al. Aspiration of gastric bacteria in antacid-treated patients: a frequent cause of postoperative colonisation of the airway. Lancet 1982;i:242-5.
22 Donowitz LG, Page MC, Mileur BL, et al. Alterations of normal gastric flora in critical care patients receiving antacid and ciimetidine therapy. Infect Control 1986;7:23-6.

23 Seegobin RD, van Hasselt GL. Aspiration beyond endotracheal cuffs. Can Anaesth Soc J 1986;33:273-9.

24 Sottile FD, Marrie TJ, Prough DS, et al. Nosocomial pulmonary infection: possible etiological significance of bacterial adhesion to endotracheal tubes. Crit Care Med 1986;14:265-70.

25 Craven DE, Lichtenberg DA, Goularte TA, et al. Contaminated medication nebulizers in mechanical ventilator circuits. Source of bacterial aerosols. Am J Med 1984;77:834-8.

26 Huxley EJ, Viroslav J, Gray WR, et al. Pharyngeal aspiration in normal adults and patients with depressed consciousness. Am J Med 1978;64:564-8.

27 Hunter JD. Effects of anaesthesia on the human immune system. Hospital Medicine 1999;60:658-63.

28 Meduri GU, Estes RJ. The pathogenesis of ventilator-associated pneumonia: II. The lower respiratory tract. Intensive Care Med 1995;21:452-61.

29 Young PJ, Ridley SA. Ventilator-associated pneumonia. Anaesthesia 1999;54:1 183-97.

30 Martin TR, Pistorese BP, Hudson LD, et al. The function of lung and blood neutrophils in patients with the adult respiratory distress syndrome. Implications for the pathogenesis of lung infections. Am Rev Respir Dis $1991 ; 144: 254-62$.

31 LaForce FM, Mullane JF, Boehme RF, et al. The effect of pulmonary edema on antibacterial defenses of the lung. J Lab Clin Med 1973;82:634-8.

32 Rello J, Diaz E. Pneumonia in the intensive care unit. Crit Care Med 2003;31:2544-51.

33 Guerin C, Girard R, Chemorin C, et al. Facial mask noninvasive mechanical ventilation reduces the incidence of nosocomial pneumonia. A prospective epidemiological survey from a single ICU. Intensive Care Med 1997; 23: 1024-32.

34 Nourdine K, Combes P, Carton MJ, et al. Does noninvasive ventilation reduce the ICU nosocomial infection risk? A prospective clinical survey. Intensive Care Med 1999;25:567-73.

35 Hillman KM, Riordan T, O'Farrell SM, et al. Colonization of the gastric contents in critically ill patients. Crit Care Med 1982;10:444-7.

36 Cook D, Guyatt G, Marshall J, et al. A comparison of sucralfate and ranitidine for the prevention of upper gastrointestinal bleeding in patients requiring mechanical ventilation. Canadian Critical Care Trials Group. N Engl J Med 1998;338:791-7.

37 Prod'hom G, Leuenberger P, Koerfer J, et al. Nosocomial pneumonia in mechanically ventilated patients receiving antacid, ranitidine, or sucralfate as prophylaxis for stress ulcer. A randomized controlled trial. Ann Intern Med 1994; 120:653-62.

38 Driks MR, Craven DE, Celli BR, et al. Nosocomial pneumonia in intubated patients given sucralfate as compared with antacids or histamine type 2 blockers. The role of gastric colonization N Engl J Med, 1987;317:1376-82.

39 Hubmayr RD, Burchardi H, Elliot M, et al. American Thoracic Society Assembly on Critical Care; European Respiratory Society; European Society of Intensive Care Medicine; Societe de Reanimation de Langue Francaise. Statement of the 4th international consensus conference in critical care on ICUacquired pneumonia-Chicago, Illinois, May 2002. Intensive Care Med 2002; 28:1521-36.

40 Webster NR. Importance of position in which patients are nursed in intensivecare units. Lancet 1999;354:1835-6.

41 Drakulovic MB, Torres A, Baver TT, et al. Supine body position as a risk factor for nosocomial pneumonia in mechanically ventilated patients: a randomised trial. Lancet 1999;354:1851-8.

42 Torres A, Gatell JM, Aznar E, et al. Re-intubation increases the risk of nosocomial pneumonia in patients needing mechanical ventilation. Am J Respir Crit Care Med 1995; 152:137-41.

43 Rouby JJ, Laurent $P$, Gosnach $M$, et al. Risk factors and clinical relevance of nosocomial maxillary sinusitis in the critically ill. Am J Respir Crit Care Med 1994;3:776-83.

44 Holzapfel L, Chevret S, Madinier G, et al. Influence of long-term oro- or nasotracheal intubation on nosocomial maxillary sinusitis and pneumonia: results of a prospective, randomized, clinical trial. Crit Care Med 1993;21:1132-8.

45 Ferrer $M$, Baver T, Torres $A$, et al. Effect of nasogastric tube size on gastroesophageal reflux and microaspiration in intubated patients. Ann Intern Med 1999; 130:991-4.

46 Bonten MJ, Gaillard CA, van der Hulst R, et al. Intermittent enteral feeding: the influence on respiratory and digestive tract colonization in mechanically ventilated intensive-care-unit patients. Am J Respir Crit Care Med 1996; 154:394-9.

47 Cerra FB, Benitez MR, Blackburn GL, et al. Applied nutrition in ICU patients. A consensus statement of the American College of Chest Physicians. Chest 1997; 111:769-78.

48 Nseir S, Di Pompeo C, Pronnier P, et al. Nosocomial tracheobronchitis in mechanically ventilated patients: incidence, aetiology and outcome. Eur Respir J 2002;20:1483-9.

49 Wunderink RG. Radiologic diagnosis of ventilator-associated pneumonia Chest 2000;117:188-90S.

50 Meduri GU, Mauldin GL, Wunderink RG, et al. Causes of fever and pulmonary densities in patients with clinical manifestations of ventilatorassociated pneumonia. Chest 1994;106:221-35.

51 Fabregas N, Ewig S, Torres A, et al. Clinical diagnosis of ventilator associated pneumonia revisited: comparative validation using immediate post-mortem lung biopsies. Thorax 1999;54:867-73. 
52 Jordi Rello, Jose Artur Paiva, Jorge Baraibar, et al. International conference for the development of consensus on the diagnosis and treatment of ventilatorassociated pneumonia. Chest 2001;120:955-70.

53 Luna CM, Videla A, Mattera J, et al. Blood cultures have limited value in predicting severity of illness and as a diagnostic tool in ventilator-associated pneumonia. Chest 1999;116:1075-84

54 Gibot S, Cravoisy A, Levy B, et al. Soluble triggering receptor expressed on myeloid cells and the diagnosis of pneumonia. $N$ Engl J Med 2004:350:451-8.

55 Sanchez-Nieto JM, Torres A, Garcia-Cordoba F, et al. Impact of invasive and noninvasive quantitative culture sampling on outcome of ventilator-associated pneumonia. Am J Respir Crit Care Med 1998;157:371-6.

56 Marquette CH, Copin MC, Wallet F, et al. Diagnostic tests for pneumonia in ventilated patients: prospective evaluation of diagnostic accuracy using histology as a diagnostic gold standard. Am J Respir Crit Care Med 1995;151:1878-88.

57 Sauaia A, Moore FA, Moore EE, et al. Diagnosing pneumonia in mechanically ventilated trauma patients: endotracheal aspirate versus bronchoalveolar lavage. J Trauma 1993;35:512-17.

58 Ruiz M, Torres A, Ewig S, et al. Noninvasive versus invasive microbial investigation in ventilator-associated pneumonia: evaluation of outcome. Am J Respir Crit Care Med 2000;162:119-25.

59 Fagon JY, Chastre J, Wolff $M$, et al. Invasive and noninvasive strategies for management of suspected ventilator-associated pneumonia. A randomized trial. Ann Intern Med 2000;132:621-30.

60 Guerra LF, Baughman RP. Use of bronchoalveolar lavage to diagnose bacterial pneumonia in mechanically ventilated patients. Crit Care Med 1990; 18:169-73.

61 Sole Violan J, Fernandez JA, Benitez AB, et al. Impact of quantitative invasive diagnostic techniques in the management and outcome of mechanically ventilated patients with suspected pneumonia. Crit Care Med 2000;28:2737-41

62 Shorr AF, Sherner JH, Jackson WL, et al. Invasive approaches to the diagnosis of ventilator-associated pneumonia: a meta-analysis. Crit Care Med 2005;33:46-53.

63 Torres A, El-Ebiary M. Bronchoscopic BAL in the diagnosis of ventilatorassociated pneumonia. Chest 2000;117:198-202S.

64 Wimberley N, Faling $\sqcup$, Bartlett JG. A fiberoptic bronchoscopy technique to obtain uncontaminated lower airway secretions for bacterial culture. Am Rev Respir Dis 1979;119:337-43.

65 Cook DJ, Fitzgerald JM, Guyatt GH, et al. Evaluation of the protected brush catheter and bronchoalveolar lavage in the diagnosis of nosocomial pneumonia. J Intensive Care Med 1991;6:196-205.

66 Wearden PD, Chendrasekhar A, Timberlake GA. Comparison of nonbronchoscopic techniques with bronchoscopic brushing in the diagnosis of ventilator-associated pneumonia. J Trauma 1996;41:703-7.

67 Ibrahim EH, Ward S, Sherman G, et al. A comparative analysis of patients with early-onset vs late-onset nosocomial pneumonia in the ICU setting. Chest 2000;117:1434-42.
68 Rello J, Torres A, Ricart $M$, et al. Ventilator-associated pneumonia by Staphylococcus aureus. Comparison of methicillin-resistant and methicillinsensitive episodes. Am J Respir Crit Care Med 1994;150:1545-9.

69 Mehta R, Niederman MS. Adequate empirical therapy minimizes the impact of diagnostic methods in patients with ventilator-associated pneumonia. Crit Care Med 2000;28:3092-4

70 Iregui M, Ward S, Sherman G, et al. Clinical importance of delays in the initiation of appropriate antibiotic treatment for ventilator-associated pneumonia. Chest 2002;122:262-8.

71 Luna CM, Vujacich P, Niederman MS, et al. Impact of BAL data on the therapy and outcome of ventilator-associated pneumonia. Chest 1997;111:676-85.

72 Fowler RA, Flavin KE, Barr J, et al. Variability in antibiotic prescribing patterns and outcomes in patients with clinically suspected ventilator-associated pneumonia. Chest 2003;123:835-44.

73 Wunderink RG, Rello J, Cammarata SK, et al. Analysis of two double-blind studies of patients with methicillin-resistant Staphylococcus aureus nosocomial pneumonia. Chest 2003;124:1789-97.

74 Kollef MH. Inadequate antimicrobial treatment: an important determinant of outcome for hospitalized patients. Clin Infect Dis 2000;31:S131-8.

75 Ibrahim EH, Ward S, Sherman G, et al. Experience with a clinical guideline for the treatment of ventilator-associated pneumonia. Crit Care Med 2001;29:1109-15.

76 Torres A, Ewig S. Diagnosing ventilator-associated pneumonia. N Engl J Med 2004;350:433-5.

77 Chastre J, Wolff M, Fagon JY, et al. PneumA Trial Group. Comparison of 8 vs 15 days of antibiotic therapy for ventilator-associated pneumonia in adults: a randomized trial, JAMA 2003;290:2588-98.

78 Kollef MH. Prevention of hospital-associated pneumonia and ventilatorassociated pneumonia. Crit Care Med 2004;32:1396-405.

79 Rumbak MJ, Newton M, Truncale T, et al. A prospective, randomized, study comparing early percutaneous dilational tracheotomy to prolonged translaryngeal intubation (delayed tracheotomy) in critically ill medical patients. Crit Care Med 2004;32:1689-94.

80 Kress JP, Pohlman AS, O'Connor MF, et al. Daily interruption of sedative infusions in critically ill patients undergoing mechanical ventilation. N Engl J Med 2000;342:1471-7.

81 Sirvent JM, Torres A, El-Ebiary $M$, et al. Protective effect of intravenously administered cefuroxime against nosocomial pneumonia in patients with structural coma. Am J Respir Crit Care Med 1997;155:1729-34.

\section{ANSWERS}

1. (A) T, (B) F, (C) F, (D) T; 2. (A) F, (B) F, (C) F, (D) F; 3.

(A) T, (B) T, (C) F, (D) T; 4. (A) F, (B) F, (C) F, (D) F; 5. (A)

$\mathrm{F}$, (B) F, (C) T, (D) F. 